\title{
São João em tempos de Covid-19: os impactos da pandemia do novo coronavírus nas experiências de participantes de quadrilhas juninas no interior cearense
}

Feast of Saint John in times of COVID-19: the impacts of the new coronavirus pandemic on the experiences of dancers in Quadrilhas Juninas in the state of Ceará

\author{
Thiago Silva de Castro' \\ https://orcid.org/0000-0003-0652-8589 \\ thiagonoda@hotmail.com \\ Antonio Cristian Saraiva Paiva" \\ https://orcid.org/0000-0001-6478-1297 \\ cristianspaiva@gmail.com \\ I Universidade Federal do Ceará - Fortaleza, CE, Brasil \\ Doutorando em Sociologia (bolsista Capes) \\ " Universidade Federal do Ceará - Fortaleza, CE, Brasil \\ Pesquisador Pq 2/CNPq
}




\title{
Resumo
}

Com foco nas experiências dos participantes de quadrilhas juninas da cidade de Sobral, localizada na região norte do estado do Ceará, este artigo propõe apresentar os impactos da pandemia de Covid-19 no cotidiano dos indivíduos. A partir de uma reflexão sobre as interseccionalidades de gênero, sexualidade, classe e raça entrecruzadas nas experiências sociais e subjetivas de dançarinos de tradicionais festejos de São João, analisa-se os efeitos da interrupção dos trabalhos dos grupos juninos, em função do estado de quarentena decretado pelo governo cearense, sobre seus cotidianos e sobre os modos de preparar as quadrilhas. Com base nessa realidade etnográfica, amparando-se diretamente nos discursos expressos pelos participantes diante das circunstâncias geradas pelo novo coronavírus, busca-se pensar sobre como essas pessoas se sentem afetadas social e subjetivamente pelo estado pandêmico.

Palavras-chave: quadrilha junina; Covid-19; interseccionalidade; pessoas LGBTI+.

\begin{abstract}
Focusing on the experiences of participants in traditional June festivals (square dance) in the city of Sobral, located in the northern region of the State of Ceará - Brazilian Northeast, this article proposes to present the impacts of the COVID-19 pandemic on the daily lives of individuals. Based on a reflection on the intersectionality of gender, sexuality, class and race intertwined in the social and subjective experiences of the June festivals dancers (square dance), we analyze the effects of the interruption in activities of the dancers to the state of quarantine decreed by the Ceará government, about their everyday lifes and about the ways of preparing the square dances. Based on this ethnographic reality, based directly on the speeches expressed by the participants in this context, given the circumstances generated by the new coronavirus, we seek to think about how these people feel socially and subjectively affected by the pandemic state.
\end{abstract}

Keywords: Feast of Saint John; COVID-19; intersectionality; LGBTI+ people. 


\title{
Este ano não terá São João: e agora?
}

\author{
E agora, José? \\ A festa acabou, \\ a luz apagou, \\ o povo sumiu, \\ a noite esfriou, \\ e agora, José?
}

Carlos Drummond de Andrade

Nada poderia traduzir melhor o sentimento dos quadrilheiros juninos ${ }^{1}$ da cidade de Sobral, ${ }^{2}$ no interior do Ceará, do que esse clássico poema de Carlos Drummond de Andrade quando o governador Camilo Santana (PT) decretou estado de quarentena em todo território cearense, o que ocorreu no dia 18 de março de 2020. O Ceará, desde os primeiros momentos em que a pandemia de Covid-19 se abateu sobre o Brasil, demonstrou ser um dos estados mais afetados pela doença em função da localização estratégica da capital como ponto de circulação internacional de pessoas em fluxos de viagens. ${ }^{3}$ De repente, a necessidade do isolamento social obrigou a maior parte da população a se resguardar em casa. Apenas serviços considerados essenciais se mantiveram.

1 "Quadrilheiro" é o termo usado pelos participantes das quadrilhas juninas para se autodefinirem. O termo tem um alcance geral, servindo para designar pessoas que se envolvem com os processos de produção de uma quadrilha, seja dançando, coordenando ou apoiando de outras formas. O interesse por esse recorte empírico deve-se ao trabalho doutoral em curso, em que analisamos as expressividades de gênero e sexualidade no contexto das quadrilhas juninas da região de Sobral, a partir dos processos de subjetivação expressos pelos participantes desse universo, conforme explicitado mais à frente.

2 Situada a aproximadamente $240 \mathrm{~km}$ de Fortaleza, capital cearense, a cidade de Sobral é considerada a principal cidade da região norte do estado e uma das mais importantes do interior do Ceará. Com uma população estimada em 210.711 habitantes (Instituto Brasileiro de Geografia e Estatística, 2020), o município exerce influência cultural e econômica em praticamente toda sua região, sendo um importante centro industrial, universitário e político no estado. A cidade se caracteriza por congregar um intenso fluxo de indivíduos que vivem em municípios vizinhos, que buscam cotidianamente os serviços ofertados por ela.

3 Até o momento em que escrevemos este trabalho, soma-se o número de 373.417 casos de infecção no Ceará, com 10.476 mortes registradas. Em Sobral, são 14.128 casos, com 328 mortes confirmadas por Covid-19 (Boletim..., 2020). 
Naquela altura, os componentes das quadrilhas juninas da cidade já se reuniam há vários meses, preparando suas coreografias, encenações, musicalidades e figurinos. $O$ caráter espetacular e competitivo das quadrilhas juninas em diferentes estados brasileiros já foi amplamente discutido em suas várias nuances por autoras e autores como Menezes Neto (2009, 2015), Noleto (2016), Castro (2018), dentre outros nomes. Semelhante ao que Cavalcanti (2002) mostra em relação a manifestações populares como o Carnaval carioca e os bois-bumbás de Parintins (AM), as quadrilhas juninas hoje constituem espetáculos que mobilizam certo grau de sofisticação artística, articulando diferentes linguagens estéticas com a intenção de promover uma comunicação tanto com o público quanto com as comissões julgadoras que avaliam os trabalhos dos grupos nos concursos juninos, que, no caso do Ceará, acontecem ao longo dos meses de junho e julho na forma de circuitos nas diferentes microrregiões do estado.

O processo de construção desses espetáculos costuma variar entre as quadrilhas, mas seu tempo médio costuma girar entre seis e nove meses. Os grupos de quadrilha junina são, desse modo, parte viva do cotidiano de seus participantes, que constroem com esse universo uma forte relação de afeto e pertencimento, a ponto de muitas pessoas se referirem a eles como uma segunda família. Os bastidores da festa são permeados por uma intensa sociabilidade que ajuda a moldar seus interesses e comportamentos, uma vez que as quadrilhas juninas passam a não representar para tais indivíduos apenas uma diversão, mas uma atividade que integra suas vidas tal qual a família, o trabalho, os estudos, etc. Utilizando a premissa de Le Breton (2019, p. 138), para quem a expressão das emoções constitui campo fértil na busca por entender o peso da vida social na experiência dos indivíduos, é possível dizer que os quadrilheiros se encontram permanentemente influenciados pelos acontecimentos do universo junino e sendo tocados por eles. Do mesmo modo, seus não acontecimentos também se abatem sobre essas pessoas com intensidade semelhante, o que foi possível perceber a partir das limitações impostas pela pandemia do novo coronavírus.

Mas o que representou essa paralisação para os quadrilheiros? Essa é uma pergunta que merece atenção, e tratar dela nos permitirá trazer algumas reflexões sobre o perfil dos indivíduos que, em sua maior parte, fazem parte desse universo. Os dados etnográficos que dão sustentação ao presente texto são parte da experiência de um de seus autores no campo das quadrilhas juninas 
cearenses, em especial dos grupos juninos da cidade de Sobral, na região norte do Ceará, uma das áreas mais afetadas pela disseminação do contágio por Covid-19 no estado. A interrupção dos trabalhos nos leva a pensar no que esfriou nessa festa em função da pandemia e como isso impactou os modos de fazer-se pessoa/quadrilheiro e as sociabilidades associadas a essa criação coletiva. E agora, José? Ou seria João? Na busca por responder a essas questões, o santo pouco importa. Por outro lado, as experiências dos quadrilheiros importam bastante.

\section{Espetáculo das margens: um encontro de identidades dissidentes e/ou desconformes}

É possível dizer que, hoje, já há uma gama significativa de escritos dedicados aos sentidos articulados pelas festas juninas no Brasil. Trabalhos como o de Luciana Chianca $(2006,2007)$ são exemplos contundentes desse acervo. A autora dedicou parte de seus esforços para demonstrar como os festejos juninos são ressignificados nos espaços urbanos, a partir da construção de uma antítese entre o citadino e o homem do campo. Nesse sentido, o São João, como também são conhecidas as festas juninas, representaria um ressurgimento festivo do interior nas cidades, uma vez que as populações destas seriam compostas por imigrantes das zonas rurais ou por seus descendentes.

Tais nuances das festas juninas, que falam sobre seus aspectos históricos e culturais no imaginário da população brasileira, são comuns nos estudos sobre as manifestações da chamada cultura popular. Menos comum nos parecem ser as reflexões sobre o perfil dos sujeitos que protagonizam tais expressões na contemporaneidade, suas nuances e peculiaridades identitárias. Se é verdade que o São João e as quadrilhas juninas, enquanto brinquedo popular que a ele se liga, encontram suas raízes no complexo processo de transformação da sociedade brasileira que, no século $\mathrm{XX}$, transita do status de sociedade rural para urbana, hoje, as questões colocadas pelo perfil dos sujeitos que protagonizam essa festa parecem refletir fenômenos mais alinhados a um panorama contemporâneo.

Analisando os processos sociais vivenciados no universo das quadrilhas juninas da cidade de Belém, Rafael Noleto (2020) é bastante assertivo ao 
afirmar que algo que une os quadrilheiros é o fato de pertencerem a uma condição periférica. Segundo o autor, para além da caracterização mais convencional de periferia relacionada a indicadores socioeconômicos e de localização espacial nos centros urbanos, esses sujeitos ocupam periferias de gênero e sexualidade, que são atravessadas por experiências subalternas de classe social. O perfil descrito por Noleto também se aplica aos quadrilheiros sobralenses, a saber, jovens em sua maior parte oriundos da periferia da cidade, que é o principal centro econômico da região norte cearense. Há ainda aqueles vindos de municípios vizinhos menores e que ou estudam em Sobral ou se deslocam especialmente para participar de grupos juninos do município.

O público quadrilheiro é formado por uma juventude bastante diversa, que se desloca pelo território da cidade para participar dos ensaios dos grupos, que geralmente ocorrem em quadras de escolas, associações e até em praça pública. As quadrilhas de Sobral estão todas sediadas em bairros populares, alguns deles dispondo de zonas marcadas pelo estigma da violência e habitadas por famílias de baixa renda, representando importante elemento de entretenimento e sociabilidade para os moradores. A despeito desses traços sociais marcantes, o aspecto que talvez mais identifique os grupos juninos hoje seja a forte presença de pessoas LGBTI $+{ }^{4}$ que hoje representam a base de sustentação dessa manifestação. Como notou Eduardo Di Deus (2014) no contexto das quadrilhas juninas de Rio Branco, percebemos que esses grupos parecem representar um processo de inclusão para pessoas que costumam ser discriminadas em virtude de suas identidades sexuais e/ou de gênero. Hayeska Barroso (2017) chama atenção para o fato de que tais pessoas estão presentes nos diferentes setores do espetáculo, exercendo uma influência direta na produção e nos rumos que ele tem tomado, nos levando a crer que os saberes/fazeres dos sujeitos LGBTI+ têm se tornado fundamentais dentro da manifestação.

4 A sigla LGBTI+, hoje adotada pela Associação Brasileira de Lésbicas, Gays, Bissexuais, Travestis, Transexuais e Intersexos (ABGLT), agrupa identidades políticas associadas a populações de lésbicas, gays, bissexuais, travestis, transexuais, intersexuais e demais coletivos dissidentes em relação à norma cissexual e heterocêntrica e ao esquema binário de sexo-gênero. Representa uma espécie de atualização da sigla LGBT, dando maior visibilidade a pautas e estratégias políticas emergentes dos coletivos. Variações do acrônimo, contemporaneamente encontradas, são: LGBTQ+, LGBTQI+, LGBTQIA+, dentre outras. Ver Associação Brasileira de Lésbicas, Gays, Bissexuais, Travestis, Transexuais e Intersexos (2017) e Reis (2018). 
Outro aspecto a ser ressaltado é o fato de a maior parte dos quadrilheiros se reconhecerem como pardos ou pretos. Tal constatação expõe mais um marcador social a ser levado em conta no exercício de tentar identificar esses sujeitos, denotando a necessidade de perceber essa expressão cultural a partir de uma lente interseccional. Autoras como Brah e Phoenix (2004) e Akotirene (2019), no contexto dos estudos de gênero, indicam a interseccionalidade ${ }^{5}$ como uma ferramenta indispensável para a compreensão das identidades, que não devem ser tomadas como universais, uma vez que os sujeitos são atravessados a um só tempo não só pelo gênero, mas pela raça, classe e sexualidade, não estando esses marcadores isolados. Uma leitura interseccional nos chama atenção para a necessidade de perceber os sujeitos entrecruzados por esses marcadores não como sobreposições de camadas, mas como produtores simultâneos de efeitos sobre os corpos e subjetividades dos indivíduos.

Diante de tal caracterização, faz sentido pensar os grupos de quadrilha junina como espaços liminoides (Turner, 2015), situados às margens dos grandes processos sociais, absorvendo sujeitos marcados por experiências também liminares. As quadrilhas se mostram dotadas de um potencial antiestrutural, pois formam um processo social dentro do qual os sujeitos veem sua criatividade corpóreo-subjetiva estimulada, ao contrário do que relatam acontecer no exterior desse espaço, em contextos como o trabalho, o ambiente escolar e até mesmo a família. O universo quadrilheiro (termo êmico encontrado na pesquisa) promove o encontro de sujeitos em geral subalternizados seja pela sexualidade, identidade de gênero, raça ou classe social. A sociabilidade praticada nos bastidores da construção dos espetáculos juninos revela subjetividades e corporalidades mais fluidas, apresentadas na performance social de diferentes experiências LGBTI+ que encontram nesse espaço não apenas um refúgio, mas a possibilidade de expressão subjetiva e corporal com maior liberdade. Nesse sentido, o universo quadrilheiro é capaz de levantar problemas para o que Turner

5 Interseccionalidade é um conceito pensado por feministas negras a fim de tensionar a inseparabilidade de raça e gênero, diante da inobservância do feminismo branco em relação à raça e do movimento negro em relação ao gênero. Para a jurista norte-americana Kimberlé Crenshaw, a perspectiva interseccional é importante por se apropriar de eixos de poder que costumam ser pensados como distintos e mutuamente excludentes, como raça, etnia, sexo e gênero. Para ela, tais sistemas frequentemente se sobrepõem e se cruzam nas experiências sociais, “[...] criando intersecções complexas nas quais dois, três ou quatro eixos se entrecruzam" (Crenshaw, 2002, p. 177). 
chama de homem social estrutural, traço das experiências liminares nas sociedades pós-industriais. Para os sujeitos desse universo, o estado de isolamento social imposto pela pandemia de Covid-19 representa não apenas a suspensão de atividades básicas, mas também o confinamento compulsório em um mundo carregado de opressões que os atravessam diretamente, e, como consequência, a suspensão do espaço de sociabilidades clementes (Paiva, 2009), permeadas pela brincadeira, pela dança e pela festa, configurado pelo universo da festa junina.

\section{Vai ter São João... mas cada qual na sua casa! ${ }^{6}$}

O São João, para mim, morreu. Foi assim que um participante do grupo junino Estrela do Luar, do qual também participo,7 definiu seu sentimento quando, no início do mês de junho, questionei em um grupo de WhatsApp como os quadrilheiros que lá estavam se sentiam diante da interrupção das atividades em virtude do novo coronavírus. A resposta me tomou de rompante, pois naquele momento acreditava ser possível manter vivo um sentimento de entusiasmo diante dos símbolos da festa. Foi então que compreendi que mantinha com a manifestação junina uma relação diferente daquela dos demais quadrilheiros, já que a condição de acadêmico e pesquisador me permitia transitar por espaços e interesses que me possibilitavam certo desligamento daquele universo. Esse fato denunciou marcadores de diferenciação em nossas experiências e, por outro lado, me proporcionou o distanciamento necessário para refletir sobre a fala tão fatalista de meu parceiro de grupo.

A frase em questão não falava de uma morte concreta, mas simbólica. E não se referia necessariamente às comemorações sazonais do mês de junho tal como conhecidas popularmente, mas à parte que a quadrilha junina representava em seu cotidiano, que não era pequena. No momento em que as medidas sanitárias impostas pelo governo estadual decretaram o estado de quarentena, os trabalhos juninos já estavam bastante intensos na cidade de Sobral, e havia

6 Trecho da música "Arraiá virtuá", da banda cearense Mastruz com Leite.

7 O texto, embora produzido a quatro mãos, adota, aqui, propositalmente a primeira pessoa, visando apreender melhor a experiência etnográfica direta de um dos autores. 
grande efervescência nos seus bastidores: todo um processo de construção cênica e coreográfica, bem como de produção de indumentárias, já vinha sendo posto em prática há pelo menos três meses. Interromper isso foi como parar um fluxo interpretado como natural pelos quadrilheiros, daí a sensação de morte. A parada desses processos artísticos representou também a brusca interrupção da interação social vivenciada nesses meandros, que fazia literalmente parte do dia a dia dos sujeitos, o que parece ficar evidente no que expressa Patrick, rapaz gay dançarino da quadrilha Estrela do Luar:

Eu fiquei supertriste, dançar é a minha terapia que mais vejo resultado, senti um vazio porque o São João traz a minha alegria. Eu pirei. Tentei me agarrar na esperança, mesmo sendo cancelado. Eu ainda tinha esperança, mas quando chegou em maio e eu vi que não ia ter, me bateu uma bad, mas aí eu me confortei só na esperança e na ansiedade para que chegue 2021. (Depoimento registrado em 13 de julho de 2020).

A tonalidade afetiva que modula a narrativa de Patrick - significada como tristeza, vazio e bad - pode ser entendida como forma de reação à perda do São João, reação próxima daquilo que a psicanálise teoriza como melancolia. $\mathrm{Na}$ tentativa de desenvolver uma compreensão acerca dos efeitos do que classifica como estado melancólico, Freud (2013) propõe uma comparação entre esse sentimento e o luto. Para ele, os aspectos que os caracterizam são os mesmos, pois ambos seriam reações à perda de um objeto querido, que pode ser tanto uma pessoa pela qual se nutre um afeto quanto uma abstração ou idealização. A diferença entre esses sentimentos residiria no fato de que enquanto o luto promove um movimento de superação da perda por meio do desinvestimento libidinal no objeto perdido, convencendo o sujeito da não mais existência deste, na melancolia há uma identificação narcísica com esse objeto, que passa a viver no próprio eu, promovendo um tipo de sofrimento que direciona sua energia a si próprio. Freud argumenta que no luto se sabe explicitamente o que se perdeu, o que facilita a superação dessa perda; já na melancolia, embora se saiba quem ou o que morreu, não é possível saber conscientemente o que de fato vai junto com isso que se desfaz.

Naturalmente, não se pode afirmar que o sentimento dos quadrilheiros em relação à ausência do universo simbólico do São João é proporcional 
à melancolia descrita por Freud. Entretanto, parece ser inegável que o isolamento social, que de uma só vez retirou das pessoas o convívio com a festa e a sociabilidade por ela proporcionada antes, durante e depois de sua expressão, é acompanhado nos quadrilheiros de um profundo sentimento de perda. No que concerne à elaboração de tal perda, entretanto, percebe-se que esse processo se encontra mais próximo à melancolia do que do luto freudiano, pois longe de ser um desinvestimento emocional no universo junino enquanto objeto, durante o isolamento social, percebe-se uma intensificação no interesse por ele, um aumento da identificação. Apesar da ausência, essa energia não é dispersada para outro objeto, ela volta constantemente ao eu.

Santa Clara (2007) afirma que Freud supõe, no quadro melancólico, uma perda cuja natureza se encontra mais no campo ideal do que físico, algo que se ligaria ao campo afetivo de sua relação direta com o objeto. Desse modo, percebe-se que aquilo que se perde não diz respeito apenas ao outro que "deixa de existir", mas ao próprio sujeito que sente, já que a identificação narcísica com o objeto perdido o integra ao ego, assim "a presença do objeto pela incorporação, mesmo que ele já tenha morrido ou tenha sido perdido na realidade, é uma verdade falseada e não poderá corresponder com a 'plena' satisfação que, antes, o eu obtinha com o objeto 'real'" (Santa Clara, 2007, p. 137). Percebe-se que o efeito da perda do São João para os quadrilheiros é a incorporação de uma sensação que dá conta da permanência subjetiva dessa manifestação cultural em suas vidas, em uma tentativa de evitar a dor maior resultante da ausência da quadrilha junina em virtude do isolamento social.

A interrupção das atividades juninas, levando em consideração as características identitárias da maior parte dos quadrilheiros, tem um impacto subjetivo avassalador sobre suas experiências, produzindo um conjunto de perdas que fazem da renúncia à manifestação cultural uma tarefa bastante penosa, como demonstra a fala de Patrick. Uma dessas perdas, como já indicado, é o próprio fluxo das experiências juninas cotidianas, sentidas, como demonstra a própria frase que abre esta seção, como uma morte. Outra forma de expressão de afeto melancólico pode ser percebida à luz das teorizações de Judith Butler (2019a) e Didier Eribon (2008), que, mediante a apropriação da teorização freudiana sobre as reações à perda, referem-se a uma "melancolia de gênero", ou a uma "melancolia gay", própria de sujeitos que possuem experiências de gênero e/ou sexualidade dissidentes da matriz cis-heterocentrada que rege nossa 
sociedade. Tal melancolia seria fruto de um sentimento de desconformidade causado pela perda compulsória do objeto heterossexual, considerado padrão na experiência binária do mundo social ocidental, produzindo efeitos melancolizantes de sujeição psíquica (Paiva, 2012), traduzindo-se em sentimento de inadequação às expectativas sociais sobre os corpos e subjetividades.

Esses delineamentos conceituais sobre os afetos melancolizantes, ensaiados para pensar processos de regulação sociopsíquica de corpos e subjetividades no contexto do isolamento social e da solidão imposta pela pandemia vivida no país, podem nos ajudar a pensar a experiência sentida da perda das festas de São João. A quadrilha junina, assim, mais do que um mero contexto de diversão, parece constituir-se enquanto espaço vital de recriação/recreação do eu e de expressão corporal menos regulado, agregando experiências sociais permeadas pelas dissidências de gênero, sexuais, raciais ou de classe, que frequentemente são recusadas pelos regimes de subjetivação socialmente dominantes. Daí que a perda instantânea desses espaços de sociabilidade clementes seja sentida como um grande impacto. Isso também se soma a experiências de caráter individual, como demonstra a fala de Patrick a seguir:

[O ambiente da quadrilha me faz bem] por conta dos acontecimentos da minha vida pessoal. O São João me ajudou a "amenizar" a dor de dois lutos, dentre outros traumas e angústias [que enfrento]. Eu vejo como uma válvula de escape, sem falar também que eu amo me "montar de dama", é terapêutico. (Depoimento registrado em 13 de julho de 2020).

Patrick traz em sua performance corporal-subjetiva uma explícita experiência de fluidez de gênero. No primeiro ensaio da quadrilha em 2020, chegou ao local com uma enorme peruca loira e sapato de salto alto, demarcando que deveria ser lida como uma dama, não como cavalheiro. Era esse o lugar que lhe interessava ocupar no contexto artístico do grupo, experiência de gênero que fora então respeitada. Conforme me confidenciou em entrevista, sua performance drag não pode ser confortavelmente demonstrada em todos os espaços sociais em que se insere, sendo a quadrilha junina um dos poucos lugares onde Mia, sua persona feminina, pode vir à tona com mais tranquilidade. Expressões que dizem que a quadrilha é uma terapia, ou que é um espaço onde se poder ser livre, são talvez as mais recorrentes entre os indivíduos que compõem esses grupos. 
Elas podem apressadamente ser interpretadas como trivialidades, a menos que se entenda quem, em geral, são essas pessoas, muitas vezes marcadas por experiências estigmatizadas pelos padrões binários que orientam as relações sociais em nossa sociedade.

Marcos, que em 2020 completaria 13 anos ininterruptos participando do universo junino de Sobral, percebe a situação imposta pelo isolamento social como um prejuízo para as pessoas que compõem as quadrilhas juninas da cidade. Apesar de entender a importância da medida para o combate ao coronavírus, ele aponta que a ausência dos grupos quadrilheiros representa não apenas a falta de uma atividade cultural, mas a supressão de um espaço de reconhecimento simbólico das potencialidades dos sujeitos que promovem tal manifestação:

O São João serve como palco pra essas pessoas - no caso, nós - terem esse momento de estrelismo, de ser notado, de ser observado, de ser aplaudido, de ser reconhecido [...] é uma forma que não só a periferia, como também a classe LGBT, criou pra gritar, pra dizer que tá ali presente, que também tem talento, que consegue desenvolver qualquer tipo de atividade que seja, que também é artista, que também merece respeito. Então essa falta, dessa inserção, dessa prática, da própria atividade, ela vem sendo assim, de fato, olhando pela vertente geral, muito avassaladora... E assim, eu fico muito triste, de certa forma, em "não poder aglomerar" dentro da quadrilha, não poder de fato matar a saudade, ter esse momento de descontração, tirar o estresse, mas a gente fica nessa esperança que em breve a gente possa de fato reviver tudo isso novamente, que a gente possa continuar lutando pela causa também, mostrar o quanto nossa classe não é somente desvalorizada, mas que também somos artistas de respeito, que fazemos um trabalho de qualidade, e é mais ou menos isso que eu sinto enquanto LGBT, enquanto negro, enquanto da periferia e enquanto quadrilheiro. (Depoimento registrado em 22 de janeiro de 2021).

Judith Butler (2019b) nos chama atenção para o fato de que, do ponto de vista político, também somos constituídos em virtude daquilo que define como vulnerabilidade social de nossos corpos, observando que o corpo se constitui como território do desejo, da vulnerabilidade física e como lugar de afirmação e exposição pública. A autora destaca essa vulnerabilidade como um traço 
eminentemente humano, efeito da constituição social de nossos corpos, que se encontram sujeitos a perdas, expostos à violência e ameaçados pela ação de outros. Butler nota, porém, que essa vulnerabilidade comum à condição humana está desproporcionalmente distribuída entre os diferentes grupos sociais que compõem nosso mundo, fazendo com que determinadas vidas estejam fortemente protegidas dos fenômenos que atentam contra tal vulnerabilidade, enquanto outras não desfrutam da mesma proteção, o que tem como consequência um rebaixamento da importância de suas vidas/existências.

A pandemia de Covid-19 parece materializar a percepção de Butler, na medida em que demonstra como nenhum corpo se encontra imune à doença, já que ninguém esteve livre das consequências causadas pela disseminação do vírus. O modo como se tem lidado com essas consequências, entretanto, revela enormes desigualdades na forma como a vulnerabilidade, advinda da exposição ao contexto pandêmico, se manifesta. Diante disso, pensar na experiência quadrilheira como sendo permeada por vulnerabilidades é entendê-la como representativa de vivências desprivilegiadas, se apreciadas a partir das normas, expectativas e moralidades do padrão hegemônico de humanidade. $\mathrm{O}$ isolamento social imposto como medida de enfrentamento à pandemia do novo coronavírus veio potencializar essas vulnerabilidades.

Assim, o vazio expresso pelos quadrilheiros, diante desse cenário, está diretamente atrelado às suas experiências periféricas, em sentido amplo do termo, que encontram um tipo de reconhecimento no universo da manifestação cultural que ora permanece ausente enquanto o isolamento perdurar. Mas, como aponta Marcos, que, além de brincante, ${ }^{8}$ é também um profissional que presta serviços para diferentes grupos juninos como coreógrafo, o impacto dessa ausência é também econômico:

[...] pra mim foi muito ruim, porque eu lembro que eu já estava com contrato fechado, e tivemos que entrar num acordo por conta que de fato a pandemia iniciou bem no começo do ano mesmo... Recebi um valor referente ao trabalho que eu já tinha desempenhado, e pra mim foi complicado porque tipo... É uma grana, é um valor financeiro que acaba de certa forma auxiliando na renda que eu já

8 "Brincante" é um outro termo bastante utilizado para definir a experiência dos quadrilheiros, sendo este usado com mais frequência para se referir a quem dança quadrilha. 
tenho diária... E você passar um ano, durante uma crise mundial, um processo de pandemia, sem aquela renda que você tinha, que de certa forma lhe auxiliava em muitas coisas, gente... É muito ruim, a falta! (Depoimento registrado em 22 de janeiro de 2021).

Do ponto de vista dos ganhos financeiros que a atividade junina lhe proporciona anualmente, Marcos afirma que pouco tem podido fazer para compensar a renda perdida com a pandemia, mas conta que tem tentado compensar a falta da manifestação cultural como pode, integrando grupos no WhatsApp sobre o assunto, participando de lives sobre São João e se fazendo presente em eventos virtuais organizados por quadrilhas juninas ou páginas digitais ${ }^{9}$ dedicadas a essa manifestação no estado do Ceará. No fim de 2020, disse ter acompanhado on-line shows protagonizados por regionais ${ }^{10}$ que executaram canções típicas dos repertórios juninos, assistido a vídeos das apresentações de seu grupo junino para matar a saudade, e participado de outras programações direcionadas ao público quadrilheiro na internet: "Essa é a maneira que eu encontro pra, de certa forma, resgatar essa memória que eu tenho do São João, e pra reviver, mesmo à distância, essa questão do movimento junino em si", disse.

Se, por um lado, alguns participantes do universo junino têm buscado nas atividades virtuais a possibilidade de compensar a ausência da manifestação, outras pessoas, por sua vez, ainda encontram dificuldade de lidar com o cancelamento das festas juninas em virtude da pandemia. "Acredito que eu nem tenha parado pra pensar justamente como uma forma de fuga, pra não sentir a dor doer, né? A dor de não ter São João" - foi isso que me disse Layze (depoimento registrado em 13 de julho de 2020), quadrilheira autodeclarada negra, quando a questionei sobre o que a ausência do São João significava para ela. Layze expressa um tom melancólico diante da falta da quadrilha, já que, segundo ela, a atmosfera junina invade os espaços do cotidiano como uma

9 No Ceará existem alguns portais dedicados exclusivamente às notícias e atividades que envolvem o universo da cultura junina no estado. Algumas dessas mídias digitais possuem grande alcance, estando presentes em plataformas como YouTube, Facebook, Instagram e Twitter. Suas equipes fazem cobertura de eventos realizados pelas quadrilhas juninas, promovem a divulgação de seus trabalhos e desenvolvem quadros e programações envolvendo pautas de interesse no universo quadrilheiro.

10 Grupos musicais pertencentes às quadrilhas. 
presença que finca suas raízes mesmo na ausência. "É muito difícil porque tudo lembra, né? Apesar dos dias parecerem ser sempre os mesmos, às vezes as redes sociais e alguns aplicativos fazem a gente lembrar", afirma. Para ela, as iniciativas de tentar fazer com que o São João permaneça vivo no campo virtual são válidas, diante da necessidade de isolamento social, mas não são suficientes para preencher o espaço deixado pela supressão abrupta do cotidiano vivenciado anualmente em sua experiência junina:

Por mais que as pessoas façam lives, principalmente lives colaborativas, façam encontros para falar sobre as temáticas que seriam trabalhadas em 2020, e que vão ser trabalhadas em 2021, é muito diferente, nada vai substituir, nada vai ocupar aquele espaço vazio que o São João 2020 deixou. Eu, no início, tinha esperança de que a pandemia fosse controlada e brevemente a gente pudesse retomar os ensaios, e quem sabe só adiar o São João, os festivais, colocar os festivais pra agosto, setembro - apesar de que isso já seria uma mudança muito drástica, né? [...] 2019 realmente a quadrilha ficou totalmente parada, e 2020 já tinha toda uma expectativa de que ia chegar e nós retomaríamos os trabalhos... Foi um baque mesmo. (Depoimento registrado em 13 de julho de 2020).

Para os quadrilheiros da cidade de Sobral, imaginar a festa sem o calor dos corpos se encontrando, tanto na dança quanto nas interações cotidianas, sem pensar nos encontros proporcionados pelos concursos ao longo dos meses de junho e julho e, principalmente, sem pensar no grau de liberdade que o contexto das festas juninas é capaz de lhes fornecer é como esvaziar parte significativa do sentido que tais sujeitos atribuem à manifestação. Como expressou a interlocutora: "Eu acho que realmente o significado de não ter São João em 2020 é uma lacuna, acho que é isso... E uma lacuna muito dolorosa!" Para David Le Breton (2013), o sentimento de dor, ou melhor, os significados atribuídos a ele, são o resultado das condições sociais e culturais das quais o ser humano é, ele próprio, uma consequência. A trama social composta pelos atores exerce forte influência sobre seus valores e comportamentos, repercutindo em seus sentimentos. Assim sendo, a possibilidade de vivenciar um São João estando cada qual em sua casa, por meio de artifícios tecnológicos como lives e vídeos nas redes sociais ameniza, mas não estanca por completo a dor da perda: "Vou fingir que 2020 não existiu", disse Layze. 


\section{Até o próximo São João: considerações finais}

Percebe-se que, do ponto de vista das subjetividades dos sujeitos que fazem a manifestação junina no contexto apresentado neste trabalho, fazer parte de uma quadrilha junina ou, como muitos dizem, dançar São João, possui significados que transcendem em muito a ideia da festa como um ritual sazonal, vinculado a uma suposta identidade cultural nacional e/ou regional. A quadrilha se apresenta como um mundo de experiências múltiplas, marcadas fortemente pelo cruzamento de avenidas identitárias subalternizadas, interseccionando marcadores de sexualidade, gênero, classe social e raça transpassados por processos de exclusão estruturais. Enquanto espaço de sociabilidades e território de experiências e de subjetivações, ainda que marcado pelos dispositivos dominantes de regulação de corpos e identidades (Foucault, 2014), o universo das quadrilhas consegue gerar um lugar propício ao encontro de experiências forjadas em um campo liminar, situado às margens dos processos legitimados pelos saberes/poderes hegemônicos.

Essa percepção nos fornece os instrumentos necessários para acessar os impactos da pandemia de Covid-19 no cotidiano desses sujeitos, que são capazes não apenas de afetar o corpo em sua materialidade orgânica, física, mas também de impactar dimensões sociopsíquicas e culturas afetivas caras aos sujeitos. Vimos, ao discutir a produção de afetos melancolizantes, associados ao isolamento social, à solidão e ao circuito de vulnerabilidades em diversas esferas (afetivas, familiares, de trabalho, etc.), produzidos pelo cenário da pandemia que assola o país desde março de 2020, o quanto a festa junina funciona como criação coletiva "contradepressora", para usar a expressão de Kristeva (1989), por acolher formas de expressão de si, de corpos e de afetos que, sem a festa, continuam cotidianamente recusados.

Na seara das experiências sociais, a busca por ressignificar a experiência da manifestação junina cumpre alcançar seus objetivos apenas à medida que as expectativas que deveriam ter sido atendidas no São João 2020 são estendidas ao próximo São João. Até lá, segue-se esperando o momento de acender a fogueira e voltar a cumprir a marcação dos passos. 


\section{Referências}

AKOTIRENE, C. Interseccionalidade. São Paulo: Sueli Carneiro: Pólen, 2019.

ASSOCIAÇÃO BRASILEIRA DE LÉSBICAS, GAYS, BISSEXUAIS, TRAVESTIS, TRANSEXUAIS E INTERSEXOS. Estatuto social. Curitiba: ABGLT, 13 ago. 2017. Disponível em: https://42591db2-5171-4bc2-9173-225378cc4c25.filesusr.com/ugd/dcb2da_14bd10 27967a4e06a7d1b42ede2e2c99.pdf. Acesso em: 20 ago. 2020.

BARROSO, H. C. O São João é gay: horizontes interpretativos sobre as performances trans na festa junina no Ceará. Periódicus, Salvador, v. 1, n. 6, p. 179-197, abr. 2017.

BOLETIM epidemiológico novo coronavírus (COVID-19). Fortaleza: IntegraSUS: Governo do Estado do Ceará, 2020. Disponível em: https://indicadores.integrasus. saude.ce.gov.br/indicadores/indicadores-coronavirus/coronavirus-ceara. Acesso em: 30 ago. 2020.

BRAH, A.; PHOENIX, A. Ain't I a woman?: reviditing intersectionality. Journal of International Women's Studies, Bridgewater, v. 5, n. 3, p. 75-86, May. 2004. Disponível em: http://vc.bridgew.edu/jiws/vol5/iss3/8. Acesso em: 10 jun. 2020.

BUTLER, J. Problemas de gênero: feminismo e subversão da identidade. Rio de Janeiro: Civilização Brasileira, 2019a.

BUTLER, J. Vida precária: os poderes do luto e da violência. Belo Horizonte: Autêntica, 2019b.

CASTRO, T. S. de. Política das relações quadrilheiras: um estudo a partir da experiência do grupo competitivo Estrela do Luar, em Sobral/CE. 2018. Dissertação (Mestrado em Antropologia) - Centro de Ciências Humanas, Letras e Artes, Universidade Federal do Rio Grande do Norte, Natal, 2018.

CAVALCANTI, M. L. V. de C. Os sentidos no espetáculo. Revista de Antropologia, São Paulo, n. 45, p. 37-78, 2002.

CHIANCA, L. de O. A festa do interior: São João, migração e nostalgia em Natal no século XX. Natal: Editora da UFRN, 2006.

CHIANCA, L. de O. Quando o campo está na cidade: migração, identidade e festa. Sociedade e Cultura, Goiânia, v. 10, n. 1, p. 45-59, jan./jun. 2007.

CRENSHAW, K. Documento para o encontro de especialistas em aspectos da discriminação racial relativos ao gênero. Estudos Feministas, Florianópolis, v. 10, p. 171-188, jan. 2002. 
DI DEUS, E. Quadrilhas Juninas como um movimento de juventude em Rio Branco, Acre. Sociedade e Cultura, Goiânia, v. 17, n. 1, p. 75-85, jan./jun. 2014.

ERIBON, D. Reflexões sobre a questão gay. Rio de Janeiro: Companhia de Freud, 2008.

FREUD, S. Luto e melancolia: Sigmund Freud. São Paulo: Cosac Naify, 2013.

FOUCAULT, M. Microfísica do poder. Rio de Janeiro: Paz e Terra, 2014.

INSTITUTO BRASILEIRO DE GEOGRAFIA E ESTATÍSTICA. Cidades: Sobral. [Portal]. Brasília: IBGE, 2020. Disponível em: https://cidades.ibge.gov.br/brasil/ce/sobral/ panorama. Acesso em: 20 ago. 2020.

KRISTEVA, J. Sol negro: depressão e melancolia. Rio de Janeiro: Rocco, 1989.

LE BRETON, D. Antropologia da dor. São Paulo: Editora FAP-Unifesp, 2013.

LE BRETON, D. Antropologia das emoções. Petrópolis: Vozes, 2019.

MENEZES NETO, H. O balancê no arraial da capital: quadrilha e tradição no São João do Recife. Recife: Ed. do autor, 2009.

MENEZES NETO, H. Música e festa na perspectiva das quadrilhas juninas de Recife. Revista Anthropológicas, Recife, ano 19, n. 26, p. 103-133, 2015.

NOLETO, R. da S. Brilham estrelas de São João: gênero, raça e sexualidade em performance nas festas juninas de Belém/PA. 2016. Tese (Doutorado em Antropologia) - Faculdade de Filosofia, Letras e Ciências Humanas, Universidade de São Paulo, São Paulo, 2016.

NOLETO, R. da S. Regulamentos da cultura: diversidade sexual e de gênero nos concursos juninos de Belém. Estudos Feministas, Florianópolis, v. 28, n. 1, p. 1-16. 2020.

PAIVA, A. C. S. Pulsão invocante e constituição de sociabilidades clementes: notas sobre karaokê numa sauna em Fortaleza. In: ENCONTRO ANUAL DA ANPOCS, 33., 2009, Caxambu. Anais [...]. São Paulo: Anpocs, 2009. p. 1-31.

PAIVA, A. C. S. Melancolia de gênero e envelhecimento homossexual: figurações da velhice no contexto da homossexualidade masculina. In: VALE, A. F. (org.). França e Brasil: olhares cruzados sobre imaginários e práticas culturais. São Paulo: Annablume, 2012. p. 87-116.

REIS, T. (org.). Manual de comunicação LGBTI+. 2. ed. Curitiba: Aliança Nacional LGBTI: GayLatino, 2018. Disponível em: https://www.grupodignidade.org.br/wp-content/ uploads/2018/05/manual-comunicacao-LGBTI.pdf. Acesso em: 30 ago. 2020. 
SANTA CLARA, C. J. da S. Melancolia e narcisismo: a face narcísica da melancolia nas relações do eu com o outro. Mental, Barbacena, v. 5, n. 9, p. 131-150, nov. 2007.

TURNER, V. Do ritual ao teatro: a seriedade humana de brincar. Rio de Janeiro: Editora UFRJ, 2015.

Recebido: 23/08/2020 Aceito: 20/01/2021 | Received:8/23/2020 Accepted: 1/20/2021 